\title{
Comparative Study of Ma Jianzhong's and Yan Fu's Translation Views from the Perspective of Translation Ethics
}

\author{
Tian Xibo
}

\author{
Dongfang College of Zhejiang University of Finance and Economics, China \\ Received: 09 May 2021; Received in revised form: 10 Jun 2021; Accepted: 22 Jun 2021 \\ C2021 The Author(s). Published by TheShillonga. This is an open access article under the CC BY license \\ (https://creativecommons.org/licenses/by/4.0/)
}

\begin{abstract}
Ma Jianzhong and Yan Fu are translators of the same period, the former put forward the theory of "good translation", while the latter put forward "faithfulness, expressiveness, elegance". This paper discusses the influence of translation ethics on the two translators from the perspectives of the translator's educational background, translation motivation, the choice of source text, and the reproduction and reconstruction of the translator's ethics.
\end{abstract}

Keywords-translation ethics, Ma Jianzhong, Yan Fu.

\section{INTRODUCTION}

As a kind of purposeful human behavior, translation is restricted by social norms and various presuppositions of relevant value systems. Ethics, as a science about the law of behavior facts and how to standardize them, has extensive penetration. As a new interdisciplinary subject, translation ethics has a strong explanatory power to explain many translation phenomena in the field of translation. There exist quite a lot of differences between the East and the West in translation ethics. Habermas holds that "translation ethics" in the West refers to the moral cognition of interpersonal and cultural communication, and does not touch upon the ethics of translation itself.

Wang Dazhi holds that "translation ethics is how the facts of translation is regulated and how the translation behavior is standardized, which not only touches upon translation behavior, but also the subject of translation behavior. The study of translation ethics not only includes the normative study of translation, but also includes the descriptive study of translation laws or translation phenomena. In other words, translation ethics includes translator ethics such as the rules and norms in the process of translation and the description of translation phenomena including the rules and norms of translation description etc. Mr. Wang's translation ethics does not involve intermediaries such as sponsors, patrons and publishers of translation activities, nor does it take into account the social environment such as the historical background of the times in which translation activities are located, nor does it take into account the audience. (Wang Dazhi, 2009)

According to Peng Ping, "Translation ethics is a theoretical system about the relationship between ethics and translation. As a branch of translatology system, it belongs to the field of pan-translatology extending the vision of translatology to the field of ethics and morality, and studies translation from the perspective of ethics". According to her, the term of translation is not restricted to translation activities itself, but also translation theory research and translation criticism research. Peng Ping's holds that translation activities can be further divided into the motivation of translation, the motivation of choosing the original text, the choice of translation strategies, the translator's sense of responsibility, and the reader's acceptance of the translation. It is obvious that the term "translation" here is relatively broad, covering the translator, the target language audience, the translation intermediary 
such as publishers, patrons and initiators as well as the historical background of the times in which the translation is located. (Peng Ping, 2008)

From her point of view, translation ethics is the study of translation theory, which starts from the translation activity itself, on the basis of the study of translation theory, and accepts the criticism and suggestions of readers, audience, social history and era environment, that is, to consider all aspects of translation activity from the perspective of ethics and morality. (Zhou Hong, 2015)

Ma Jianzhong and Yan Fu (1854-1921) are both intellectuals who sought truth from the West in the late Qing Dynasty. The former puts forward the concept of "good translation" and the latter puts forward the concept of "faithfulness, expressiveness and elegance." From their educational background and views on Western learning, it is easy to know that the two are quite similar in many aspects. This paper will discuss the influence of translation ethics on the two translators from the perspectives of the translator's educational background, translation motivation, the choice of source text, and the reproduction and reconstruction of the translator's ethics.

\section{EDUCATIONAL BACKGROUND OF THE TWO TRANSLATORS}

Born into a Catholic family, in his childhood Ma Jianzhong entered the traditional private school to prepare for the Imperial examination. However, after the Taiping Heavenly Kingdom started in 1850 (the 30th year of Daoguang), he entered Xuhui Public School and became Li Hongzhang's Deputy Director to assist in handling Westernization in 1870. Later, with Li Hongzhang's recommendation, Ma Jianzhong was able to study abroad with Minchang students in 1877 (the third year of Guangxu) and returned home in 1880 (the sixth year of Guangxu).

Yan Fu (1854-1921) began his five-year study career in Fujian Shipping School at the age of twelve. He studied arithmetic and astronomy and other Western studies in an English-taught school. After an internship on a warship, he served in the Navy for five years and entered the Royal Naval Academy at the age of twenty three. During his study in Britain, Yan Fu studied Social Science in depth and read the works of Adam Smith, Montesquieu, Rousseau, Darwin, Spencer, Huxley and so on. Yan Fu's academic experiences and his identity as the first enlightenment thinker to systematically introduce Western learning to Chinese have important influence on his later translation behavior.

In a word, both studied abroad after receiving the new education in China, and both went abroad in 1877(the third year of Guangxu). In addition, both of them advocated learning from the West with an enlightened attitude and put forward their translation theories after summarizing their own translation experiences. Although both of them put forward their brilliant views on translation theory in the 1890s, their influence on China is completely different.

\section{TRANSLATION MOTIVATION}

$\mathrm{Xu}$ Guangqi mentioned his translation thoughts in his Almanac General Catalogue, if you want to surpass the west, you must understand them first; before you understand, you must learn to translate. From these words, we can see his hope to strengthen the army and enrich the country through translation. After the Opium War, China's long-term closed door was opened by the Western powers with force, so a large number of intellectuals began to seek the way to save the country under the guidance of the ideas of "using foreigners to control foreigners" and "traditional Chinese values aided with modern Western ideology", so modern translation thus started and Ma Jianzhong and Yan Fu were among the advocators.

Ma Jianzhong has the opinion that "to know both thyself and others is victorious forever", and translation plays an important part in this process. He further points out that translation is "the currently urgent task" it is urgent to translate "the original articles of government decrees governing education" rather than translate "only for practical use". In this way, we can provide reference for scholar-officials. (Ma Jianzhong, 1960) As an early reformist, Ma Jianzhong judged the situation and realized that it was not enough to translate Natural Science books alone. He also proposed to translate "books of politics, religion, laws and regulations, education, the classics of making and using, the evolution of ancient and modern times, and the accumulation and dispersion of goods and wealth in various countries" (Ma Jianzhong, 1960). But unfortunately "he was restrained by his work, but his ambition was not achieved".

Yan $\mathrm{Fu}$ clearly pointed out in his article On the 
Translation of The Wealth of Nations with Liang Qichao "translation is to spread the thought of civilization and the state of the people". bu Qi was born in the Sinian. At the turn of 19th and 20th centuries, he witnessed the same kind of danger, and thinks translation is the only way to repay the nation and the people. (Luo Xinzhang, 2009)It is not only hoped that students will benefit from their education, it is also hopd that the nation can read more ancient Chinese books.

Ma Jianzhong and Yan Fu were both in the late Qing Dynasty in which the country was bullied by foreign powers, and how to save China from collapse was their most concerned topics, so their translation motivation could not be separated from the purpose of saving the country. Ma Jianzhong lamented that China was bullied by the big powers, but the nation knew little about the West, so he advocated the establishment of "Translation Academies" to cultivate translation talents and to facilitate Western learning to spread in China. In contrast, Yan Fu's translation of Evolution and Ethics and Other Essays was to tell the nation that the laws of evolution in nature is also suitable for human society. Therefore, he emphasizes "survival of the fittest" and encouraged the Chinese people to strive for self-strengthening. As can be seen above, both $\mathrm{Ma}$ Jianzhong and Yan $\mathrm{Fu}$ linked translation and national Salvation together, however, they did not have the same views on how to achieve this goal.

It was during the time of the Sino-Japanese War of 1898 that Ma Jianzhong finished his On the establishment of translation Academy. Ma Jianzhong believed that translation was a long-term plan, so he advocated the establishment of "Translation Academy" to improve the quality of translation books and expand the types of translation books, so that China could learn from Western learning in an all-round way, and then change the National situation. In Yan Fu's Evolution and Ethics and Other Essays, he was advocating the reform and reform. Yan was worried about the imminent survival of the country. In response to the urgent need of the reform and reform, he awakened the People's sense of crisis of self-improvement and seed preservation. Therefore, both sholars' views on translation are related to the translation motivation of saving the nation from extinction.

\section{SELECTION OF THE SOURCE TEXT}

Ma Jianzhong put forward three kinds of books to be translated, the first is books of the current politics such as the letters of etiquette and new clauses exchanged between various countries, and the opinions of the messenger Association. The second is the books examined and revised by officials such as administration and wealth generation. The third is the books to be read in foreign schools such as the history, the source of the rise and fall of politics and religion in the past dynasties, and the books sent by algorithms, geometry.

Ma Jianzhong, who is familiar with the Western studies, was dissatisfied with books selected for translation under the guiding ideology of "middle school as the body and Western studies for practice", because these translations, cannot arouse the reader's resonance, and thus cannot realize his cultural strategic purpose of enlightening scholars and doctors and people to learn Western studies. (Xing hongjuan, 2011)

Yan Fu's translated works are all masterpieces reflecting the social, economic and political systems of Western capitalist countries, with obvious political characteristics, his translation because it is consistent with the actual financial situation of the country and to provide reference for the Chinese people. It can be said that Yan Fu's concern for the nation and the people and his desire to save Chinese culture from the troubled times are an important factor for the formation of his translation ethics of "seeking common ground".

\section{REPRODUCTION AND RECONSTRUCTION OF TRANSLATORS'}

\section{ETHICS}

According to Chesterman, the ethics of reproduction means that the translation should be faithful and the translator should translate accurately and should avoid arbitrary addition, deletion and rewrite so as to reproduce the original texts to the maximum extent. Therefore, Reproduction Ethics means that the translator should faithfully reproduce the original text which emphasizes the accuracy and faithfulness of translation.

According to Ma Jianzhong's theory of "good translation", the translator should have the ability to freely control "the characters of the translator and the translator. 
That is to say, the translator should have a good command of the source text before translation, he should also imitate the expressions and the tones as if it were the source text. Therefore, Ma Jianzhong seek for adequacy in translation which is reflected by the reproduction of translation ethics.

In the process of translation, Yan $\mathrm{Fu}$ pays more attention to the "acceptability" of the translation and the reconstruction of translation ethics. Yan Fu translated in the way of narration in the translation practice, he made a great expansion on the key parts of the original text. That is to say, he adopts a large number of additions, deletions, adaptations, and reflected his own ethical thought of "seeking common ground" through notes. From the specific historical period of China, there was an asymmetric relationship in crosscultural communication, that is, Chinese culture encountered a strong cultural impact, while Western culture was "superior" in material, institutional and spiritual aspects. It is just because of his realization of the unequal cultural differences between China and the West that Yan Fu focuses on "seeking common ground" in order to further enhance the Chinese people's sense of hardship and patriotic feelings, and to advocate the Chinese people to seek a new way to enrich the people and strengthen the country.

In his translation, he skillfully integrates the thinking of the current situation with the translation of Western Studies, selects the most concerned issues of the public, compares the Chinese traditional culture with the relevant Western Studies from many aspects, and reflects on the shortcomings of middle schools. For example, Evolution and Ethics and Other Essays subverts the traditional Chinese concept of heaven with evolutionary thoughts, The Wealth of Nations opposes the traditional concepts of China's emphasis on capital and suppression of commerce with economic liberalism, On Liberty are opposed to the Chinese feudal absolutism with the spirit of freedom and law, Elementary Lessons in Logic and A System of Logic are the intuitionism in the Chinese ideological tradition with Western logic, etc.

\section{CONCLUSION}

Translation ethics is a new perspective for Translation Studies and contributes to the objective and dialectical evaluation of translation process and results. Ma Jianzhong and Yan Fu are both in the period of social transformation.
Their similar educational experience and social environment inevitably make their translation thoughts similar in a certain sense. However, the social environments in which the translators live and their own experiences lay the foundation for their outlook on life and values, which is equivalent to finding a yardstick to explain the world, understand society and understand life. At the same time, different internal structures projected by external objects in the translator's inner world lead to different translation thoughts and strategies, thus forming different translation ethics models.

\section{REFERENCES}

[1] Ju Anbo. Domestication and foreignization: a Century-long History of Chinese Literary Translation Studies[M]. Beijing: Science Press, 2009: 4

[2] Luo Xinzhang. Collection of Translation Studies[M]. Beijing: Commercial Press, 1984.

[3] Ma Jianzhong. On the Proposed Establishment of Translation Academy. Shi kezhai notes[M]. Beijing: Zhonghua publishing house. 1960.

[4] Peng Ping. A Study of Traditional Chinese Translation Activities from the Perspective of Ethics [J]. Beijing: Foreign Language Teaching and Research Press, 2008: 281,93

[5] Xing Hongjuan. A Cultural Interpretation of Ma Jianzhong's Translation Thoughts[J]. Journal of Nanjing Agricultural University. 2011(3).

[6] Wang Dazhi. Concept Analysis of "Ethics of Translating". Foreign Languages and Their Teaching. 2009,(12).

[7] Zhou Hong. An Analysis on the Late Qing Dynasty's Literary Translation Strategy from the Perspective of Translation Ethics[J].Journal of Qiqihar University.2015, (1)

This article is part of the research results of "On Ma Jianzhong's translation activities" (2020dfy004) 